\title{
CLINICAL OUTCOME OF LAPAROSCOPIC PARTIAL CHOLECYSTECTOMY: EXPERIENCE IN A TERTIARY CARE HOSPITAL SETTING
}

\author{
Nisar Ahmed \\ Department of Surgery, MTI Khyber Teaching Hospital, Peshawar - Pakistan
}

\begin{abstract}
Objectives: To determine the outcome of Laparoscopic Partial Cholecystectomy in cases where Laparoscopic Cholecystectomy is not possible safely.

Materials \& Methods: The clinical records of patients who underwent Laparoscopic Cholecystectomy (LC) in our surgical unit (Surgical A Unit, Khyber Teaching Hospital Peshawar) between 1 January 2015 and 31 January 2019 were examined. Out of those cases where Laparoscopic Cholecystectomy could not be performed, and we had to resort to Laparoscopic Partial Cholecystectomy(LPC) were identified. The morbidity and mortality of this sub-group was analyzed.

Results: Records of total 48 patients were examined. Thirty one(65.6\%) patients were female while 17(34.4\%) were male. Mean age was 52.2 1 13.6(2SD) years. Forty one (85.4\%) cases had acute cholecystitis, 5(10.4\%) had chronic cholecystitis and $2(4.2 \%)$ had adenocarcinoma. No mortality was observed; while among the morbidities, bile leak was observed in $5(10.4 \%)$ cases and $3(6.2 \%)$ patients developed sub hepatic collections. The hospital stay was $3.44 \pm 1.2$ (Mean \pm 2 SD; range 1-5) days.
\end{abstract}

Conclusion: Laparoscopic Partial Cholecystectomy is a safe option where Laparoscopic Cholecystectomy cannot be completed safely due to intraoperative difficulty.

Key Words: Laparoscopic Partial Cholecystectomy, Laparoscopic, Cholecystectomy

This article may be cited as: Ahmed N. Clinical Outcome of Laparoscopic Partial Cholecystectomy: Experience in a Tertiary Care Hospital Setting. J Med Sci 2020 October;28(4):327-330

\section{INTRODUCTION}

Laparoscopic cholecystectomy has become the gold-standard treatment for gallstone disease..$^{1,2}$ Its advantages include less postoperative pain, early recovery and early return to work. ${ }^{3,4}$

For majority of the patients, the safe operative approach is to ensure the 'critical view of safety' during the procedure. This means dissection of the cholecysto-hepatic area to identify the anatomy of the area clearly before doing any irreversible clipping or transection. The cystic duct and artery are exposed and lower $1 / 3$ of the gall bladder is freed from the liver bed..$^{5-7}$

In certain circumstances like acutely inflamed gall bladder where the area is extremely edematous, and chronically inflamed gallbladder where fibrosis in the area

\section{Correspondence}

Dr. Nisar Ahmed

Department of Surgery, MTI Khyber Teaching Hospital,

Peshawar - Pakistan

Email: nisar.ahmed@kmc.edu.pk

Cell: $+92-321-5113569$

Date received: $11-06-2020$

Date revised: $20-08-2020$

Date accepted: $20-12-2020$ would make the identification of the above-mentioned structures extremely difficult. In such situations, insistence on dissecting into the Calot's triangle would result in misinterpretation of the anatomy and hence inadvertent injury. ${ }^{5}$ The resultant complications are potentially disastrous.

In such situations the safety exits are twofold: first to convert the case into open cholecystectomy, also known as conversion cholecystectomy and second to remove a portion of the gallbladder, described as 'partial', 'subtotal' or 'fenestrating' cholecystectomy. . $^{80}$ Laparoscopic Partial Cholecystectomy (LPC) is a safe option where Laparoscopic Cholecystectomy(LC) cannot be completed because of anatomical difficulty. ${ }^{11,12}$ In this study we evaluated the results of the cases where laparoscopic partial cholecystectomy was performed.

\section{MATERIALS AND METHODS}

Clinical and operative data of patients who underwent Laparoscopic Cholecystectomy during the period 1 January 2015 to 31 December 2019 was obtained from the medical records. All the surgeries were performed by author (having full consultant level clinical privileges) in Khyber Teaching Hospital Peshawar. Data of all the cases who underwent Laparoscopic Cholecystectomy, includ- 
ing those in which conversion to another procedure was done, was examined. All the cases were operated under General Anaesthesia in supine position. Standard four trocars were used for surgery; $10 \mathrm{~mm}$ optical infra-umbilical port, $10 \mathrm{~mm}$ epigastric port, $5 \mathrm{~mm}$ port in right hypochondrium in midclavicular line and $5 \mathrm{~mm}$ port in right hypochondrium in anterior axillary line. After initial inspection and dissection if it was found difficult to appreciate the anatomy properly and obtain the 'critical view of safety', an early decision was made to convert the case to Laparoscopic Partial Cholecystectomy as an alternative to the conventional conversion to open cholecystectomy. In LPC part of the wall of the gallbladder from the fundus to the infundibulum along with the stones was removed and extracted in an endo-bag. The mucosa of the remaining gallbladder was cauterized with diathermy. Drain was placed in all the cases.

All the cases where the procedure was converted to Laparoscopic Partial Cholecystectomy(LPC) were included in the study. The patients lost to follow up were excluded from the study. Data was recorded in SPSS ${ }^{\circledR}$ for windows. In addition to age and gender distribution; the variables studied were hospital stay, biliary leak, bile duct injuries, intraabdominal collections and 30-day mortality.

\section{RESULTS}

Retrospective data of 788 patients was examined. In 54 cases the procedure was converted to Laparoscopic Partial Cholecystectomy. A total number of 48 cases were qualified to be included in the analysis. The mean age was 52.2 \pm 13.6 (mean $\pm 2 S D)$ years, $64.6 \%(n=31)$ among them were female and $35.4 \%(n=17)$ were male. The spectrum of the intraoperative and histopathology findings were as described in Table 1.

The hospital stay was $3.44 \pm 1.2$ (mean $\pm 2 S D$; range 1-5) days. Bile leakage was the most common complication, observed in $5(10.4 \%)$ cases. In 4 cases out of those, the leak stopped spontaneously within 14 days(median 5) days post operatively. One patient required ERCP assisted sphincterotomy and biliary stenting for drainage. 3(6.2\%) patients developed sub-hepatic fluid collections (mean $26.6 \mathrm{ml}$, range $20-40 \mathrm{ml}$ ). No other major postoperative complications were noted. No mortality was observed in our case series.

Table 1: Intraoperative/ Histopathological Findings

\begin{tabular}{|l|c|c|}
\hline Findings & $\mathbf{n}$ & $\%$ \\
\hline $\begin{array}{l}\text { Acute Edematous Cholecystitis without } \\
\text { empyema }\end{array}$ & 21 & 43.5 \\
\hline $\begin{array}{l}\text { Acute Edematous Cholecystitis with } \\
\text { empyema }\end{array}$ & 14 & 29.2 \\
\hline Gangrenous gallbladder & 6 & 12.5 \\
\hline Malignancy & 2 & 4.2 \\
\hline Chronic cholecystitis with dense fibrosis & 5 & 10.4 \\
\hline
\end{tabular}

\section{DISCUSSION}

Laparoscopic Cholecystectomy, a procedure with a documented safety profile, ${ }^{3,4}$ has become the gold standard treatment for gallstone disease. Over the period of time numerous mechanisms have been devised to ensure safety of hepatic and sub hepatic structures including the bile duct system and the vascular supply in the area.,13 Any inadvertent injury if occurs may result in definitive morbidity and probably mortality as well. ${ }^{1}$ One of the techniques to ensure safety is to identify the structures within the area of cholecysto-hepatic area clearly before clipping or ligating any. ${ }^{6}$ But in certain circumstances, it is not always possible to identify the structures to a reasonable extent and an effort to dissect the area may lead to injury. ${ }^{14,15}$

For this reason, various techniques of safe-escape have been described. One is conversion of the case to open cholecystectomy ${ }^{16}$ in a bid to ensure safety; a second option is doing partial cholecystectomy, ${ }^{6,9,11-8}$ also known as damage-control cholecystectomy. With the advent of high definition visual systems and good haemostatic techniques, LPC has been evaluated over the past two decades for its safety profile. Technically in this procedure, the surgeon avoids going into the dangerous zone of possible iatrogenic injury.

Numerous review articles and original studies have been performed to evaluate the outcome of LPC in terms of safety and adequacy of symptomatic relief. $8,10-12,18,19$ The conversion rate to LPC has been variable, one review study reported that in $10.4 \%$ of patients LPC had to be adopted as a safe measure. ${ }^{10}$ In our study, we reviewed the data of 788 cases in total, and hence our conversion rate to LPC was $6.1 \%$. Hospital stay or more precisely postoperative hospital stay has been of concern in such cases. We have found that postoperative hospital stay was $3.44 \pm 1.2$ (mean $\pm 2 S D$ range $1-5$ ) days, comparable to similar findings described in other studies., ${ }^{9,17}$

The reasons for conversions to LPC are many fold, however the vast majority of cases are due to acute inflammation or the spectrum of presentations that follow like acute phlegmonous cholecystitis, empyema gallbladder, gangrene of gallbladder etc. In our study $85.2 \%$ of the cases belonged to this group though many studies fail to provide the indication or intraoperative appearance of the gallbladder. In many studies the LPC is mentioned only in the context of acute cholecystitis implying it to be the commonest indication. ${ }^{8,9}$

In all the patients included in our study, an external biliary drain was placed following LPC. A systematic review by Henneman et al, ${ }^{10}$ referencing multiple studies favour the idea of routine placement of drain, however, Chowbey et al ${ }^{19}$ and Nakajima et al ${ }^{18}$ didn't use drain routinely in all their series. Placement of drain in the opinion of many authors has the advantage of diverting drainage of free bile from the peritoneal cavity to the exterior and 
hence act a 'safety valve' to protect against biliary peritonitis.

The ultimate success of gallbladder surgery is determined by the absence of bile duct injuries and LPC is an attempt to minimize it, however, after removal of part of gallbladder the risk of bile leak remains which is quantified as the effluent from the drain placed. As most of the cases are of leak from cystic duct stump (Strasberg type A) ${ }^{1,2,13}$ and is considered to be a self limiting phenomenon ultimately stopping by itself or in persistent cases, by sphincterotomy and stent placement via ERCP. In our series $10.4 \%(n=5)$ cases developed bile leak observed in external biliary drainage bag; $80 \%(n=4)$ stopped spontaneously over the next two weeks. Only one case required an ERCP; sphincterotomy and stenting. The literature reports a variable spectrum of bile leakage after LPC, $, 111,12,17$ a review study in this context reports a mean leakage rate around $10.5 \% .^{10}$ In our study no major biliary injury requiring reconstructive surgery was noted.

Sub hepatic collections are a concern after every type of gallbladder surgery and in case of partial or fenestrating type of cholecystectomy where a stretch of redundant mucosa is left behind and there is a common presumption to expect some degree of bile/pus collection. In our series $6.2 \%$ cases developed sub hepatic collections and all of those improved with conservative treatment. In the literature the rates of sub hepatic or intra abdominal pus collections are very low..$^{8-10,12}$

\section{CONCLUSION}

Laparoscopic Partial Cholecystectomy is a safe option in situations where Laparoscopic Cholecystectomy cannot be completed safely. In this regard, large scale multicenter studies would be highly recommended.

\section{REFERENCES}

1. Strasberg SM, Hertl M SN. An analysis of the problem of biliary injury during laparoscopic cholecystectomy. J Am Coll Surg. 1995;180:101-125.

2. van de Graaf FW, Zaïmi I, Stassen LPS, Lange JF. Safe laparoscopic cholecystectomy: A systematic review of bile duct injury prevention. Int J Surg. 2018;60:164172. doi:10.1016/j.ijsu.2018.11.006

3. Macintyre IMC, Wilson RG. Laparoscopic cholecystectomy. Br J Surg. 1993;80(5):552-559. doi:10.1002/ bjs. 1800800505

4. Kim SS, Donahue TR. Laparoscopic cholecystectomy. JAMA 2018;319(17):1834. doi:10.1001/ jama.2018.3438

5. Strasberg SM. A three-step conceptual roadmap for avoiding bile duct injury in laparoscopic cholecystectomy: an invited perspective review. J Hepatobi- liary Pancreat Sci 2019;26(4):123-127. doi:10.1002/ jhbp.616

6. Conrad C, Wakabayashi G, Asbun HJ, Dallemagne $B$, Demartines $N$, Diana $M$, et al. IRCAD recommendation on safe laparoscopic cholecystectomy. Journal of Hepato-biliary-pancreatic Sciences. 2017 Nov;24(11):603-15.

7. Strasberg SM, Brunt LM. Rationale and Use of the Critical View of Safety in Laparoscopic Cholecystectomy. J Am Coll Surg.2010;211(1):132-138. doi:10.1016/j. jamcollsurg.2010.02.053

8. Strasberg SM, Pucci MJ, Brunt LM, Deziel DJ. Subtotal Cholecystectomy-"Fenestrating" vs "reconstituting" Subtypes and the Prevention of Bile Duct Injury: Definition of the Optimal Procedure in Difficult Operative Conditions. J Am Coll Surg 2016;222(1):89-96. doi:10.1016/j.jamcollsurg.2015.09.019

9. Beldi G, Glättli A. Laparoscopic subtotal cholecystectomy for severe cholecystitis: A follow-up study. Surg Endosc. 2003;17(9):1437-1439. doi:10.1007/s00464002-9128-8

10. Henneman D, Costa D, Vrouenraets B, Wagensveld B, Lagarde S. Laparoscopic partial cholecystectomy for the difficult gallbladder: a systematic review. Surg. Endosc. 2012; 27(2), 351-358. doi:10.1007/s00464012-2458-2

11. Özçınar B, Memişoğlu E, Gök AF, Ağcaoğlu O, Yanar F, İlhan M, et al. Damage-control laparoscopic partial cholecystectomy with an endoscopic linear stapler. Turkish journal of surgery. 2017;33(1):37

12. Shin M, Choi N, Yoo Y, Kim Y, Kim S, Mun S. Clinical outcomes of subtotal cholecystectomy performed for difficult cholecystectomy. ASTR 2016;91(5):226-232. doi:10.4174/astr.2016.91.5.226

13. Strasberg SM. Avoidance of biliary injury during laparoscopic chelocystectomy. J Hepatobiliary Pancreat Sci 2002;9(5):543-547. doi:10.1007/s005340200071

14. Strasberg SM, Eagon CJ, Drebin JA. The "hidden cystic duct" syndrome and the infundibular technique of laparoscopic cholecystectomy - The danger of the false infundibulum. . J Am Coll Surg 2000;191(6):661667. doi:10.1016/S1072-7515(00)00717-1

15. Chen X, Cheng B, Wang D, Zhang W, Dai D, Zhang W, et al. Retrograde tracing along "cystic duct" method to prevent biliary misidentification injury in laparoscopic cholecystectomy. Updates in Surgery. 2020 Feb 1:1-7.

16. Livingston $\mathrm{EH}$, Rege R v. A nationwide study of conversion from laparoscopic to open cholecystectomy. Am J Surg 2004;188(3):205-211. doi:10.1016/j.amj- 
surg.2004.06.013

17. Singhal T, Balakrishnan $\mathrm{S}$, Hussain A, Nicholls J, Grandy-Smith S, El-Hasani S. Laparoscopic subtotal cholecystectomy: Initial experience with laparoscopic management of difficult cholecystitis. Surgeon. 2009;7(5):263-268. Doi:10.1016/S1479666X(09)80002-4

18. Nakajima J, Sasaki A, Obuchi T, Baba S, Nitta H, Wakabayashi G. Laparoscopic subtotal cholecystectomy for severe cholecystitis. Surg Today. 2009;39(10):870875. doi:10.1007/s00595-008-3975-4

19. Chowbey PK, Sharma A, Khullar R, Mann V, Baijal M, Vashistha A. Laparoscopic subtotal cholecystectomy: A review of 56 procedures. JLAST - Part A. 2000;10(1):31-34. doi:10.1089/lap.2000.10.31
CONFLICT OF INTEREST: Authors declare no conflict of interest

GRANT SUPPORT AND FINANCIAL DISCLOSURE: NIL

\section{AUTHOR'S CONTRIBUTION}

Following authors have made substantial contributions to the manuscript as under

Ahmed N: Study design, data collection, manuscript writting

Authors agree to be accountable for all aspects of the work in ensuring that questions related to the accuracy or integrity of any part of the work are appropriately investigated and resolved. 